\title{
Effect of Bagasse and Rice Straw Cellulose Nanofibers on Physico - Mechanical Properties of Alginate Nanocomposites Films
}

\author{
M.L. Hassan, N.F. Kassem* and M. El-Sakhawy \\ Cellulose and Paper Department and "Division of Organic \\ Industries, National Research Center, Dokki, Giza, Egypt.
}

\begin{abstract}
N THIS STUDY, cellulose nanofibers (CNF) were extracted from bagasse and rice straw and used in alginate films preparation for improving physico-mechanical properties of the prepared films. $\mathrm{CNF} /$ alginate nanocomposites films were prepared by blending CNF (2.5-25 wt.\%) and alginate polymer in aqueous solution followed by casting and air drying. The nanocomposites films were characterized regarding their homogeneity using scanning electron microscopy (SEM), tensile strength and modulus of elasticity (dry and wet), and water absorption. SEM images showed homogeneous distribution of both CNF in the alginate films. The modulus of elasticity was increased by about $40-970 \%$ and $100-436 \%$, with the reinforcement of 2.5-25\% CNF for both bagasse and rice straw, respectively. However, tensile strength was not noticeably affected. The addition of CNF remarkably improved wet tensile strength also. Adding CNF to alginate resulted in reducing water absorption of films.
\end{abstract}

Keywords: Cellulose nanofibers, Bagasse, Rice straw, Alginate and Nanocomposites.

Sodium alginate, widely used in food and pharmaceutical industries, is a water soluble salt of alginic acid, a naturally occurring non-toxic polysaccharide found in all species of brown algae ${ }^{(1,2)}$. It contains two uronic acids, -(1-4)-linked dmannuronic acid (M) and -(1-4) linked 1-guluronic acid (G), and is composed of homopolymeric blocks $\mathrm{M}-\mathrm{M}$ or $\mathrm{G}-\mathrm{G}$, and blocks with an alternating sequence of $\mathrm{M}-\mathrm{G}$ blocks ${ }^{(3)}$. With regard to the excellent film forming properties of alginate, many new and original films materials have been achieved.

The production of nanoscale cellulose fibers and their application in composite materials have gained increasing attention due to their high strength and stiffness combined with low weight, biodegradability, and renewability ${ }^{(4)}$. Application of $\mathrm{CNF}$ in polymer reinforcement is a relatively new research field ${ }^{(5)}$. The main reason to utilize CNF in composite materials is that one can potentially exploit the high stiffness of the cellulose crystal for reinforcement.

Agricultural residues are an important source for cellulose fibers in different areas of the world. Bagasse and rice straw are among the most widely used

${ }^{*}$ Corresponding author, e-mail: nesrine.kassem1@gmail.com 
lignocellulosic materials for paper and composite manufacture in countries that have no forests ${ }^{(6)}$.

In this study, CNF were isolated from bleached bagasse and rice straw pulps then blended in different ratios with alginate. The resulting films were subjected to several testing to examine their homogeneity, tensile strength, modulus of elasticity and water absorption.

\section{Experimental}

\section{Materials}

Sodium alginate $(M v=1.2 \times 105, \mu=280 \mathrm{mPa}$ s $)$ was purchased from Shanghai Chemical Reagent Co. (Shanghai, China).

Bleached kraft bagasse pulp was kindly supplied by Qena Company for Pulp and Paper, Qena, Egypt. Chemical composition of bagasse was: $\alpha$-cellulose $70.6 \%$, pentosans $26.8 \%$, ash $0.82 \%$, and degree of polymerization (DP) of 1174 .

Unbleached rice straw pulp was kindly supplied by Rakta Company (Alexandria, Egypt), and bleached in the laboratory using sodium chlorite/acetic acid. Chemical composition of bleached rice straw pulp was $61.9 \alpha$-cellulose, $22.5 \%$ hemicelluloses, $16.8 \%$ ash, and $15.4 \%$ silica.

\section{Methodology \\ Isolation of bagasse and rice straw cellulose nanofibers}

The pulps were first disintegrated by high-shear mixer using pulp suspensions of $2 \%$ consistency. The fibers were then refined using high-shear ultrafine friction grinder, or so called supermass colloider (MKCA6-2, Masuko Sanguo, Japan) and passed through the instrument up to 30 times. The gap between the discs was adjusted to $9 \mathrm{~mm}$. The refined fibers were homogenized using a two-chamber high-pressure homogenizer (APV-2000, Denmark) after being diluted with water to $1 \%$ consistency and passed through the instrument for one time. The pressure was kept at 40 bar in one chamber and 400 bar in the other chamber ${ }^{(7)}$.

\section{Preparation of films}

Polysaccharides nanocomposite films were prepared from sodium alginate and cellulose nanofibers of bagasse or rice straw by solution casting. A solution of sodium alginate was prepared by dissolving the sodium alginate $(2 \mathrm{w} / \mathrm{v})$ in distilled water at $70^{\circ} \mathrm{C}$ under stirring for $30 \mathrm{~min}$. After complete dissolution, glycerol $(0.25 \mathrm{~g} / \mathrm{g}$ of alginate) was added as a plasticizer to enhance film flexibility, decrease brittleness and facilitate their detachment from the petri dishes. Subsequently, the desired amount of nanofibrillar cellulose (2.5-25\%) was added slowly into the alginate solution. The mixture was then stirred at 1000 rpm for $6 \mathrm{hr}$. Then, the mixture was homogenized using a homogenizer at 10,000 rpm for $5 \mathrm{~min}$ at room temperature (Wiggen Hauser, D-500,) followed by sonication using ultrasound equipment (Misonix, S-4000, USA) for 5-10 min at Egypt. J. Chem. 58, No. 3 (2015) 
$50 \%$ amplitude (sequence $1 \mathrm{~min}$ ) and left to stand until removal of trapped air bubbles. The resulting solution was degassed under vacuum for $30 \mathrm{~min}$ followed by slow stirring for $4 \mathrm{hr}$ to remove all the bubbles. After that, the film-forming solution of the NFC-alginate suspension was cast poured onto petri dishes which were $9 \mathrm{~cm}$ in diameter and oven dried at $40^{\circ} \mathrm{C}$ for approximately $24 \mathrm{hr}$. The dried films were then removed from the petri dishes and stored in desiccators containing saturated magnesium nitrate solution at $25^{\circ} \mathrm{C}$ and $52.89 \%$ relative humidity until being used.

\section{Characterization of films}

Tensile properties of the alginate/CNF films were measured using LLOYD Instruments LR $10 \mathrm{~K}$ universal testing machine at a crosshead speed of 2 $\mathrm{mm} /$ minute. The film's width was $1 \mathrm{~cm}$ and the gauge length was $4 \mathrm{~cm}$. At least three strips from each sample were tested and the results averaged.

The surface morphology of the films was examined with scanning electron microscopy (SEM) JEOL JXA-840) electron probe microanalyzer. Samples were coated with gold under vacuum and then examined.

water absorption of the films was examined by soaking films in water for 1 and 2 weeks then weighed.

$$
\% \text { Water Absorption }=100 *\left[\left(\mathrm{~W}_{\mathrm{t}}-\mathrm{W}_{0}\right)\right] / \mathrm{W}_{0}
$$

where $W_{0}$ is the initial weight and $W_{\mathrm{t}}$ the final weight of the film at time $t$.

X-ray diffraction patterns (XRD) were obtained using a Philips X-ray diffractometer using $\mathrm{Cu}-\mathrm{Ka}$ radiation at $40 \mathrm{kV}$ and $25 \mathrm{~mA}$.

\section{Results and Discussion}

Characterization of isolated bagasse and rice straw nanofibers

Nanofibers isolated from rice straw bleached pulp using ultrafine grinding followed by high-pressure homogenization were used with alginate polymer to prepare cellulosic nanocomposites by solution casting.

TEM of bagasse CNF is shown in Fig. 1A. The diameters of isolated bagasse nanofibers were in the range of $7-24 \mathrm{~nm}$. The diameters of isolated rice straw nanofibers were in the range from 4 to $13 \mathrm{~nm}$; even the larger microfibrils had diameter less than $100 \mathrm{~nm}$. Because of the presence of silica in high amounts $(\sim 15 \%)$ in rice straw fibers, the transmission electron microscope (TEM) images of the isolated nanofibers (Fig. 1B) showed presence of small particles in the nanoscale; energy dispersive X-ray (EDX) spectroscopy proved that these nanoparticles are silica (as will be discussed later). 


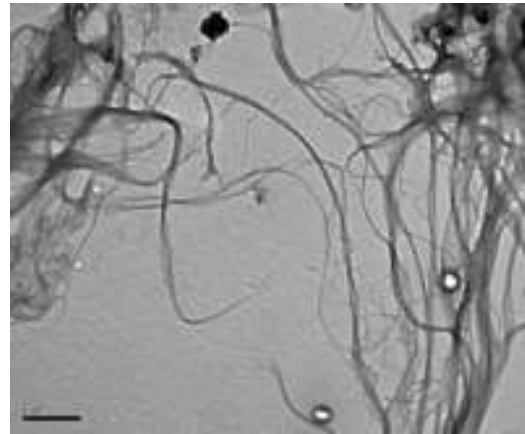

(A) Bagasse CNF

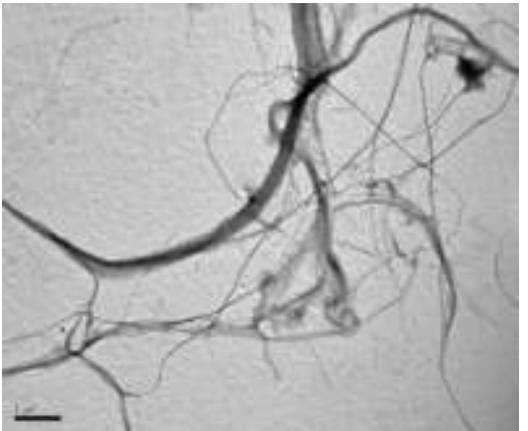

(B) Rice straw CNF

Fig.1. TEM of bagasse and rice straw nanofibers.

\section{Mechanical properties}

Thicknesses of films are presented in Table 1. The addition of $2.5 \% \mathrm{CNF}$ (bagasse or rice straw) to alginate has a significant impact on the thickness of dry films; alginate film thickness increased from 0.11 to $0.22 \mathrm{~mm}$. However, film thickness decreased again gradually by increasing the CNF content, due to its hydrophobic nature compared to alginate until it reached both $0.14 \mathrm{~mm}$ at $\mathrm{CNF}$ $25 \%$ for bagasse and rice straw. For wet films, all films have higher thicknesses at low CNF concentration and a gradual decrease in films' thickness was observed by increasing CNF content till a value of about $50 \%$ (from alginate blank film) at $25 \% \mathrm{CNF}$ addition.

TABLE 1. Nanocomposites film thickness and elongation at break \%

\begin{tabular}{|l|c|c|c|c|}
\hline \multirow{2}{*}{ Samples } & \multicolumn{2}{|c|}{ Film thickness $(\mathbf{m m})$} & \multicolumn{2}{c|}{ Elongation at break \% } \\
\cline { 2 - 5 } & Dry & Wet & Dry & Wet \\
\hline Alginate (blank) & 0.11 & 0.33 & 4.97 & 42.00 \\
\hline B2.5 & 0.22 & 0.31 & 5.93 & 48.33 \\
\hline B5 & 0.18 & 0.22 & 4.83 & 34.33 \\
\hline B10 & 0.17 & 0.23 & 5.73 & 52.67 \\
\hline B15 & 0.17 & 0.2 & 3.37 & 45.3 \\
\hline B20 & 0.15 & 0.17 & 9.87 & 30.33 \\
\hline B25 & 0.14 & 0.20 & 9.90 & 24.97 \\
\hline R2.5 & 0.22 & 0.24 & 4.97 & 62.33 \\
\hline R5 & 0.15 & 0.30 & 5.50 & 52.67 \\
\hline R10 & 0.16 & 0.18 & 3.1 & 47.67 \\
\hline R15 & 0.14 & 0.19 & 6.60 & 46.33 \\
\hline R20 & 0.15 & 0.19 & 4.07 & 35.00 \\
\hline R25 & 0.14 & 0.16 & 8.63 & 34.33 \\
\hline
\end{tabular}

Tensile strengths of CNF-alginate nanocomposites with varying $\mathrm{CNF}$ contents in dry conditions are presented in Fig. $2 \& 3$. It can be seen that alginate tensile strength decreased by different $(2.5-10 \%)$ bagasse addition by $14-25 \%$ from its value, then it increased with increasing CNF content. Addition of rice straw $\mathrm{CNF}$ to alginate film caused a decrease in tensile strength at lower addition values, $2.5-10 \%$, by $15-26 \%$; then, an improvement in tensile strength was noticed for $15-25 \%$ rice straw addition reaching about $32 \%$ higher than that of

Egypt. J. Chem. 58, No. 3 (2015) 
pristine alginate film. The initial decrease of tensile strength could be due to the decrease in extent of crosslinking of alginate because of the presence of cellulose nanofibers. Then, at higher CNF ratios, formation of network of the nanofibers compensates that decrease.

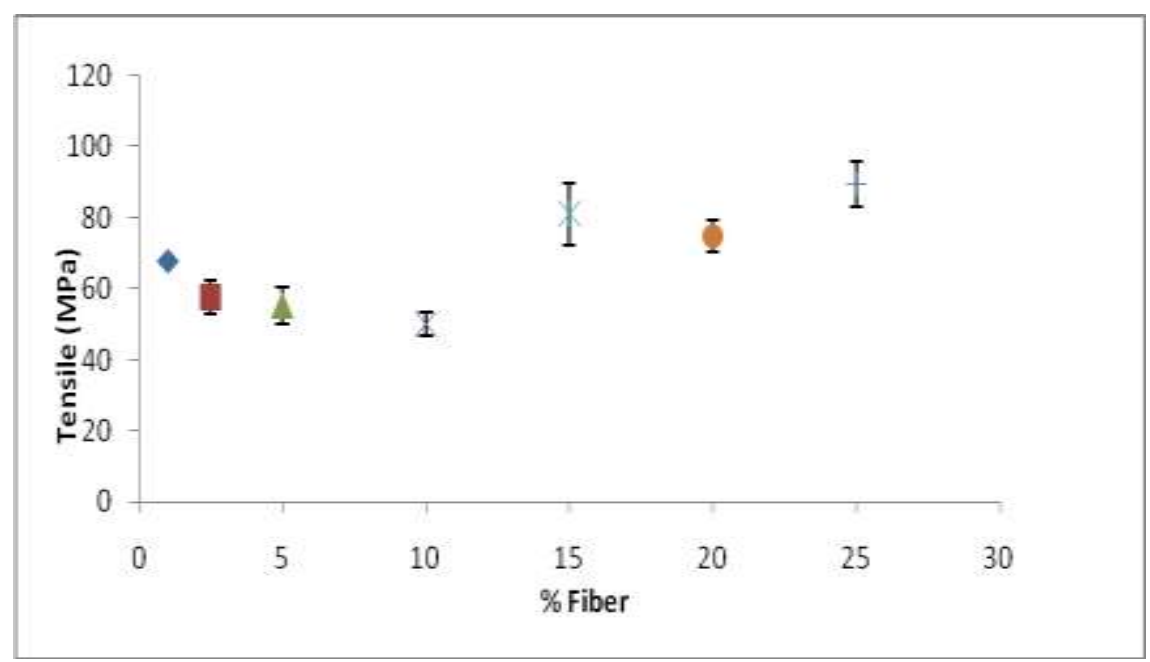

Fig. 2. Tensile strength of alginate with different bagasse contents (dry).

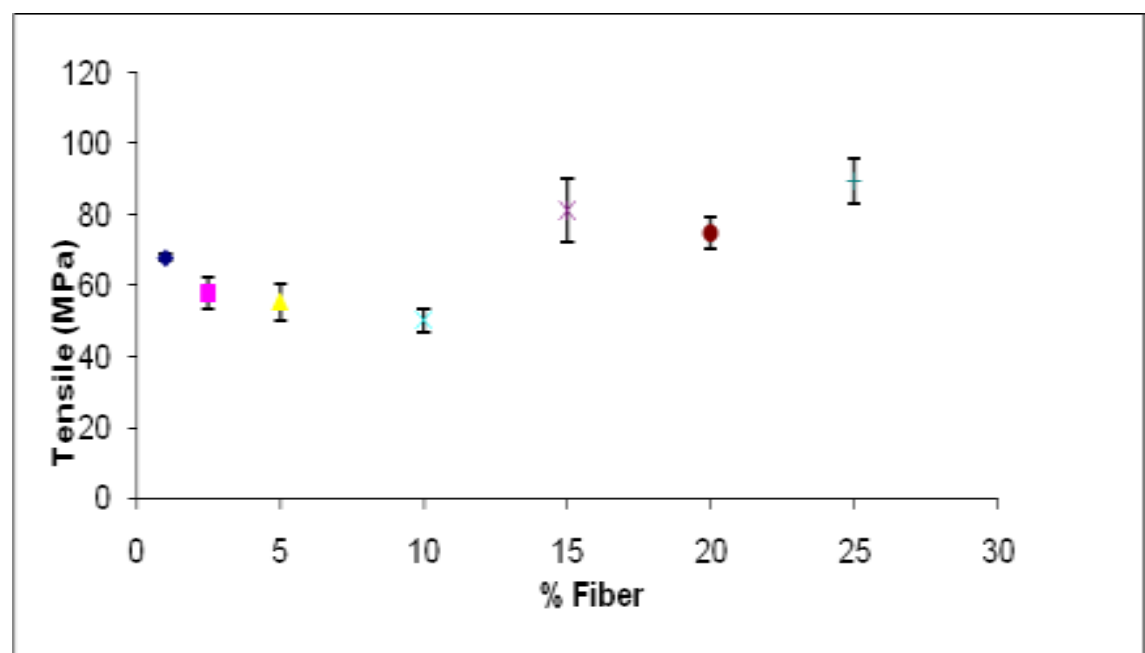

Fig. 3. Tensile strength of alginate with different rice straw contents (dry).

Wet tensile strength of the films immersed in distilled water for $15 \mathrm{~min}$ are presented in Fig. 4 and 5. The pristine alginate film had a tensile strength value of 5.27 $\mathrm{MPa}$, which is much lower than the value for dry film due to the plasticizing effect of water. By increasing bagasse CNF content from 2.5 to $10 \%$, the tensile strength increased gradually from 5.42 to $8.77 \mathrm{MPa}$, then there was a sudden decrease at 15\% (6.7 MPA) after which a slight improvement was 
noticed until $25 \%$ bagasse addition. Also, for rice straw NFC films, tensile strength value increased by increasing CNF content in the film from $5.27 \mathrm{MPa}$ for pristine alginate film to $8.78 \mathrm{MPa}$ at $10 \% \mathrm{CNF}$. At higher rice straw contents $(15-25 \%)$, the tensile strength value decreased and had a value of $6.46 \mathrm{MPa}$ at $25 \%$ rice straw addition, which is still $23 \%$ greater than that of the pristine alginate film. This reduction at high CNF content may be a result of the possible agglomeration and nonhomogeneous dispersion of CNF at high levels due to the self-networking of the nanofibers, which could reduce mechanical properties of the nanocomposite, as previously reported ${ }^{(8)}$.

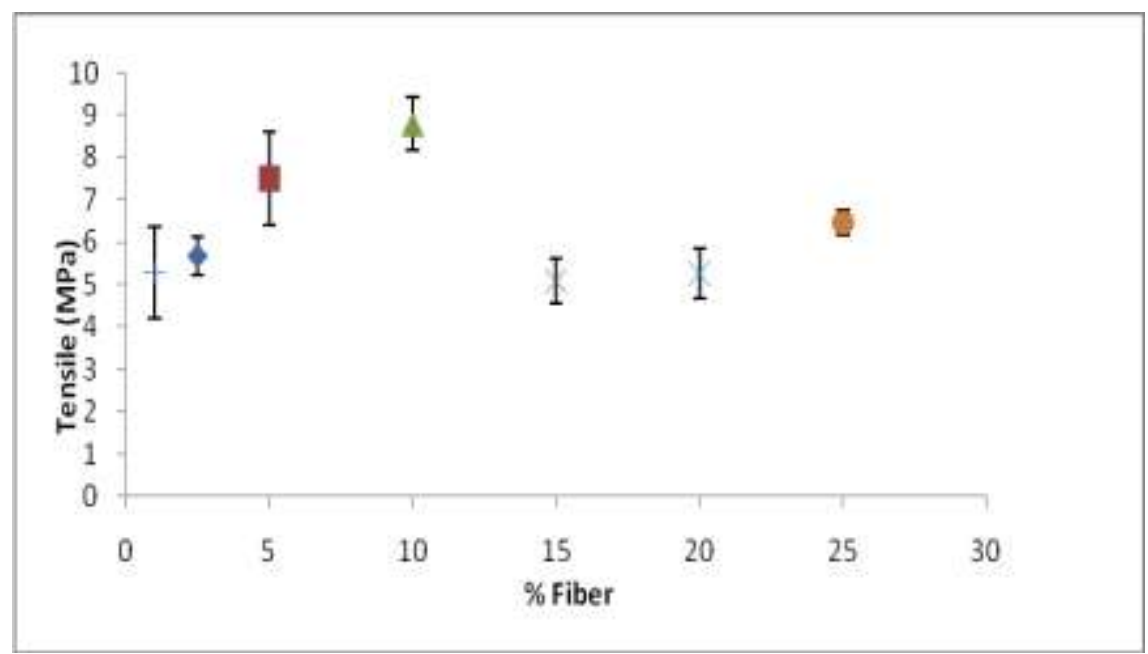

Fig. 4. Tensile strength of alginate with different bagasse contents (wet).

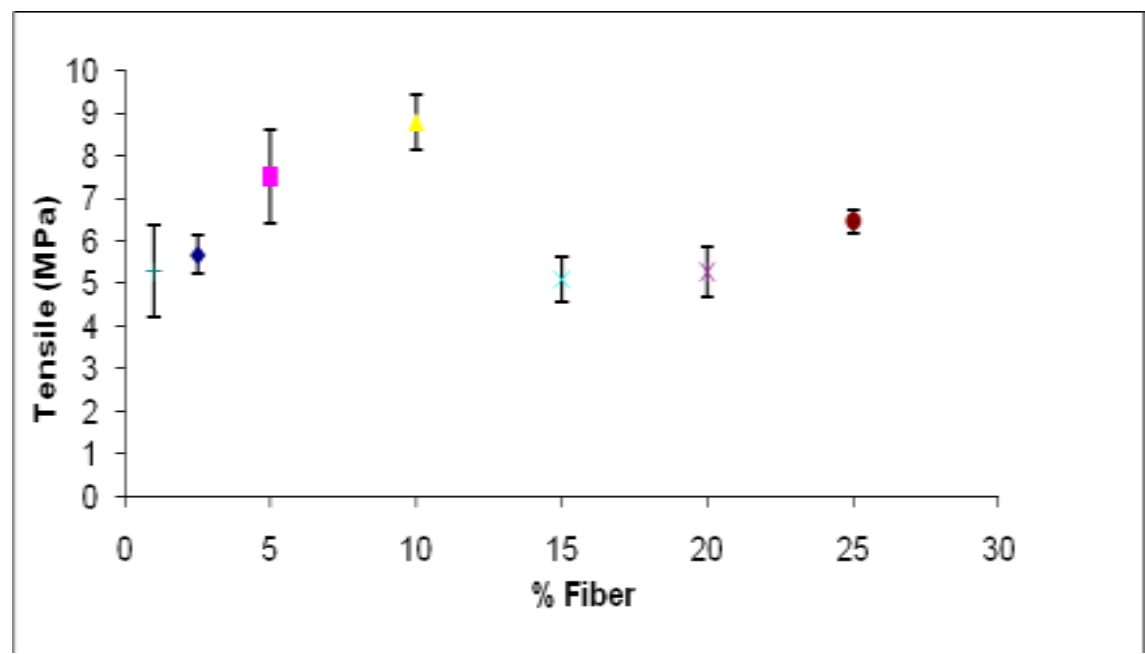

Fig. 5. Tensile strength of alginate with different rice straw contents (wet).

Egypt. J. Chem. 58, No. 3 (2015) 
The improvement of ultimate strength induced by CNF in wet samples is much greater than that calculated for dry samples. For example, ultimate strength is improved by 128 and $67 \%$ for wet $25 \%$ bagasse and $10 \%$ rice straw, respectively, compared to 11 and $32 \%$ of the value of dry $25 \%$ bagasse and $25 \%$ rice straw, respectively. This is because of both the lower swelling degree as well as the reinforcement effect provided by CNF.

Elasticity modulus is calculated from the initial linear region of the tensile stress-strain curves and the results were plotted in Fig. 6-9. It increased for dry and wet samples with increasing CNF content, due to the reinforcement of CNF. The dry pristine alginate film had a EM value of $1.4 \mathrm{GPa}$. By increasing the bagasse CNF amount (Fig. 6) from 2.5 to $25 \%$, the EM of the dry biocomposite film gradually increased by 41 to $971 \%$ than the pristine alginate film, respectively.

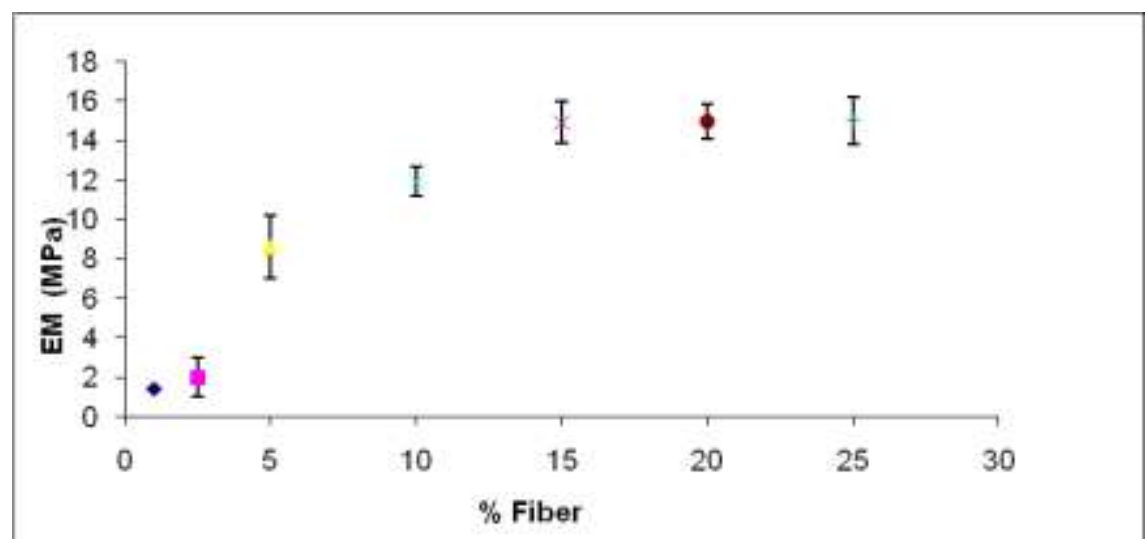

Fig. 6. Elasticity modulus of alginate with different bagasse contents (dry).

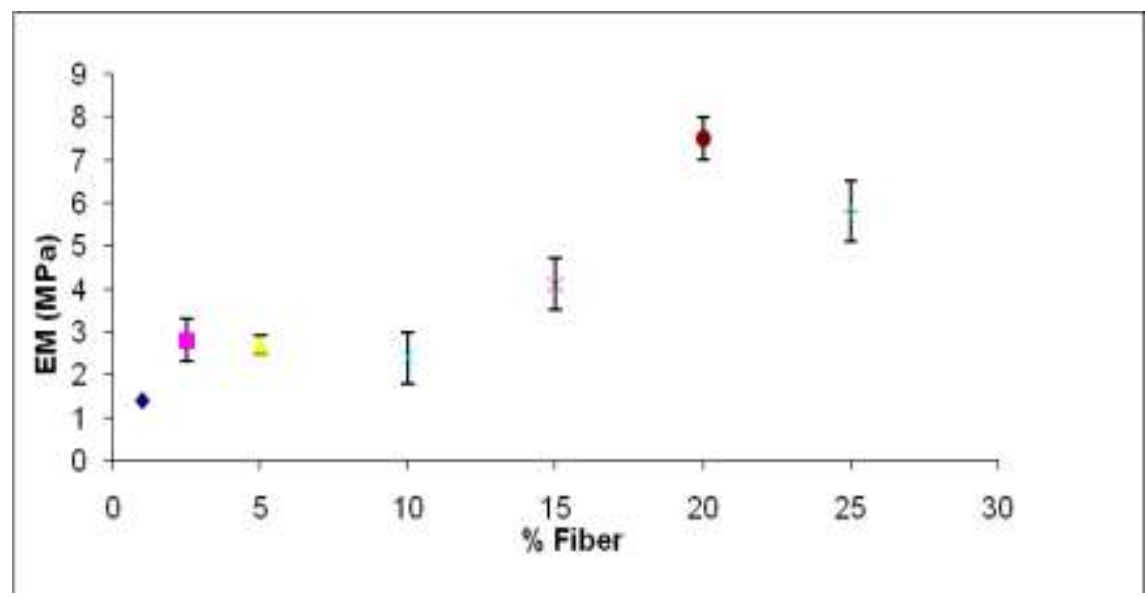

Fig.7. Elasticity modulus of alginate with different rice straw contents (dry). 


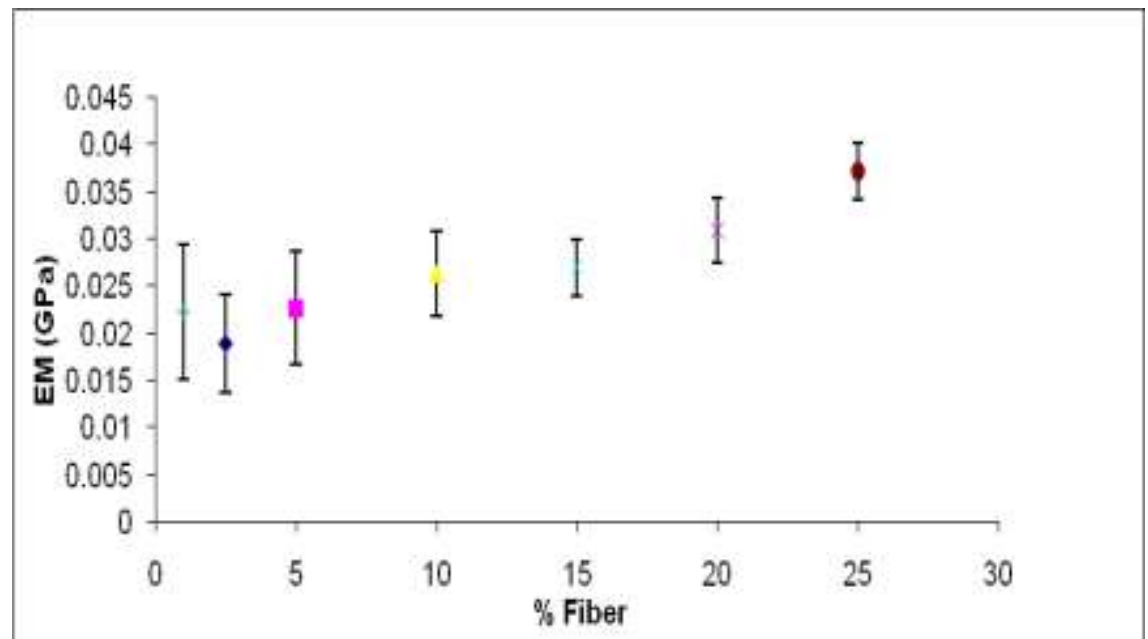

Fig. 8. Elasticity modulus of alginate with different bagasse contents (wet).

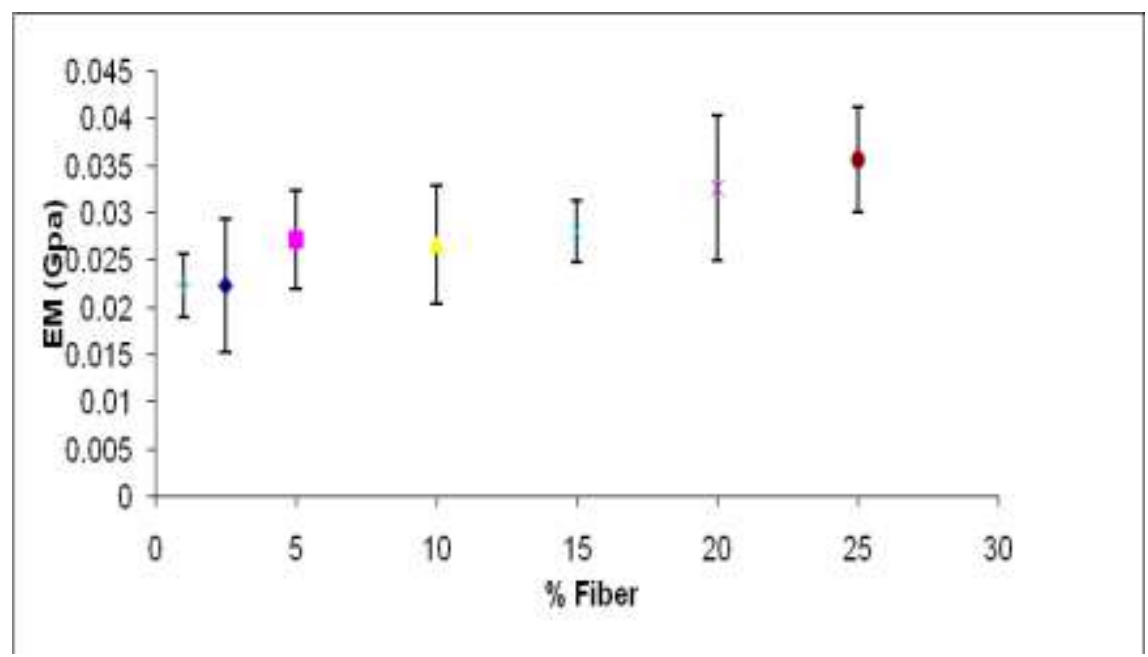

Fig. 9. Elasticity modulus of alginate with different rice straw contents (wet).

Addition of the rice straw CNF to the alginate film, (Fig. 7) increased ME values of the dry film, where $2.5 \%$ rice straw had $100 \%$ increase, and $20 \%$ rice straw had $436 \%$ higher EM values than the pristine alginate film.

Elasticity modulus for wet films improved by addition of $5 \%$ bagasse CNF by $1.4 \%$ and a steady improvement was noticed till $67 \%$ by addition of $25 \%$ $\mathrm{CNF}$ in comparison with wet alginate film. Wet EM value of pristine alginate film steadily increased by increasing rice straw CNF content by $22 \%$ at $2.5 \%$ till $58 \%$ at $25 \%$. Elasticity modulus values lost about $98.41-99.75 \%$ of its value under wet conditions.

Egypt. J. Chem. 58, No. 3 (2015) 
The enhancement in films tensile strength and elasticity modulus could be directly attributed to the reinforcement provided by the high aspect ratio and the high surface area and to the good dispersion of high-strength CNF in the film matrix and to the formation of tightly hydrogen bonded networks between fibers and matrix. It can be also related to the good interfacial interactions between the nanofibers and alginate molecules, given their similar polysaccharide structures ${ }^{(9)}$. Previous studies explained the reinforcing effect of cellulose whiskers in amorphous polymers in terms of mechanical percolation phenomenon yielded by cellulose whiskers interaction (whisker/whisker interaction) through hydrogen bonding and the formation of whiskers network within the host matrix ${ }^{(10)}$. The reinforcement by mechanical percolation requires a minimum volume fraction of the whiskers. It was also observed that the chemical nature of the cellulose fiber plays important part in the formation of strong biocomposites. Nanocomposites films prepared from bagasse nanofibers were characterized by higher tensile strength properties than films made from rice straw nanofibers. The lower strength in the case of rice straw could be due to presence of silica particles that could reduce bonding between alginate chains, $\mathrm{CNF}$, and alginate chains/CNF ${ }^{(11)}$.

Values of the elongation \% at break (E) of the films are presented in Table 1. It is known that incorporation of CNF to other polysaccharide matrix's decreases strain of the films ${ }^{(12)}$. Dry films with bagasse or rice straw CNF showed significant change in strain. In contrast, the elongation at break for the wet samples decreased with low CNF content, then decreased again. The flexibility of composite films is affected by the blending level. The elongation at break values were 52 and $34 \%$ lower than that of alginate film for $25 \%$ bagasse and $25 \%$ rice straw, respectively. Decreasing E \% with the increase of CNF content can be due to the rigid nature of the filler ${ }^{(13)}$. In fact, the incorporation of CNF restricts the motion of the alginate matrix in terms of the strong interactions between the fillers and biopolymer matrix.

It can be concluded from the results of the mechanical properties that the addition of $\mathrm{CNF}$ to the alginate films increased their strengths and module values, but decreased strain and flexibility of the film.

\section{Scanning Electron Microscopy (SEM)}

Simple eye examination of the surface of alginate-based films indicated the flexible and homogenous morphology of the films. In addition, there was no evidence of remaining air bubbles or nanoparticles sedimentation in the film samples. Nevertheless, the CNF-alginate nanocomposite film still shows good transparency when the CNF content was $25 \mathrm{wt} \%$. These results indicated good compatibility between alginate and $\mathrm{CNF}$ in the nanocomposite films that resulted in homogeneous and transparent materials. 
Scanning electron microscopy which observes the fractured surface was used for more extensive morphological inspection of biocomposite films. This test draws conclusions about the homogeneity of the composite, presence of voids, dispersion quality and possible orientation of the nanoparticles in the continuous matrix, presence of aggregates or agglomeration and sedimentation ${ }^{(14)}$. Images are from the surface faced towards the tray during the drying. The pristine alginate film (Fig. 10) has a smooth and even surface. Due to the nano-sized fibers, there was no obvious difference in morphology between neat cross-linked alginate film and cross-linked alginate with $20 \%$ bagasse (Fig.11) or rice straw CNF (Fig.12).

Overall, these SEM observations seem to support all structural modifications and improvements of mechanical and physical properties related to $\mathrm{CNF}$ incorporation in alginate films. The appropriate mechanical properties of $\mathrm{CNF}_{-}$ alginate nanocomposite films, together with the excellent biocompatibility and biodegradability of CNF and alginate and the high transparency, offer potential for the nanocomposites to be used as transparent edible films and coatings, artificial skin and wound dressings ${ }^{(15)}$.

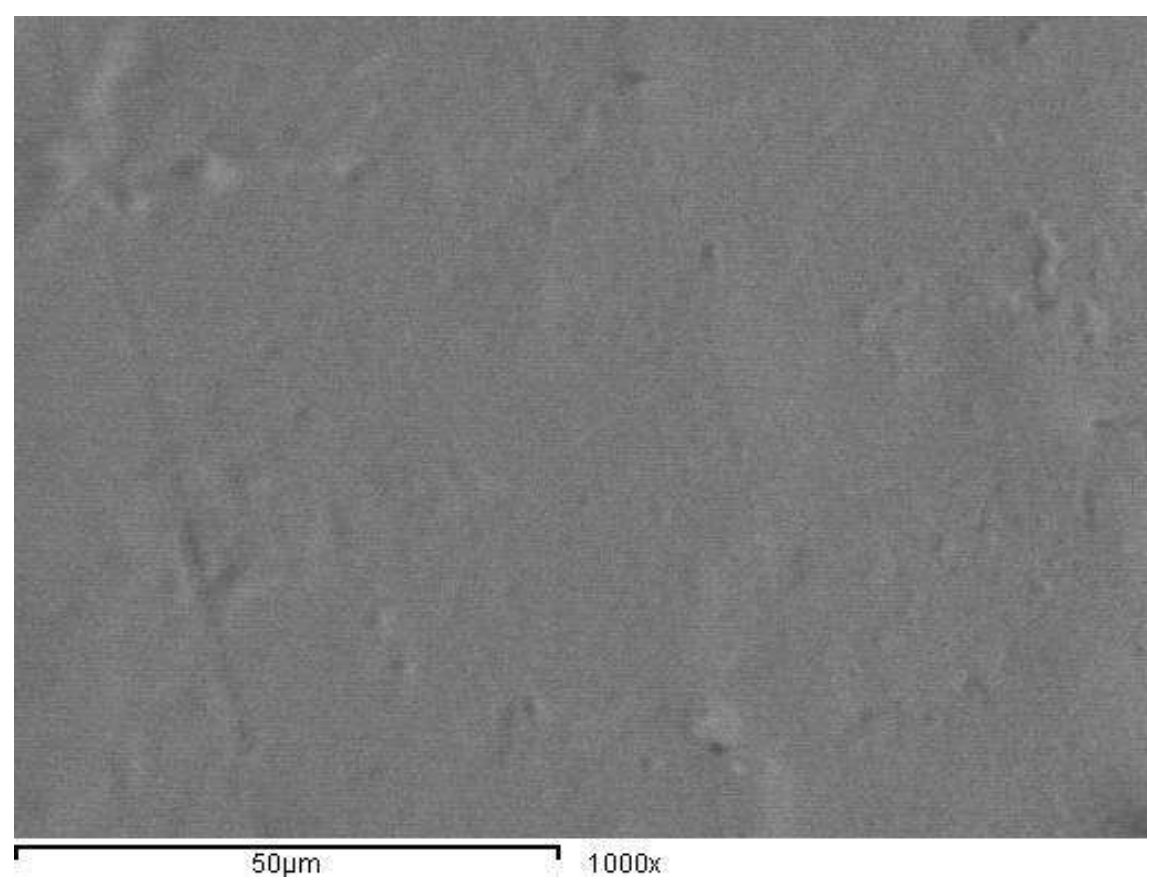

Fig. 10. SEM of alginate (blank).

Egypt. J. Chem. 58, No. 3 (2015) 


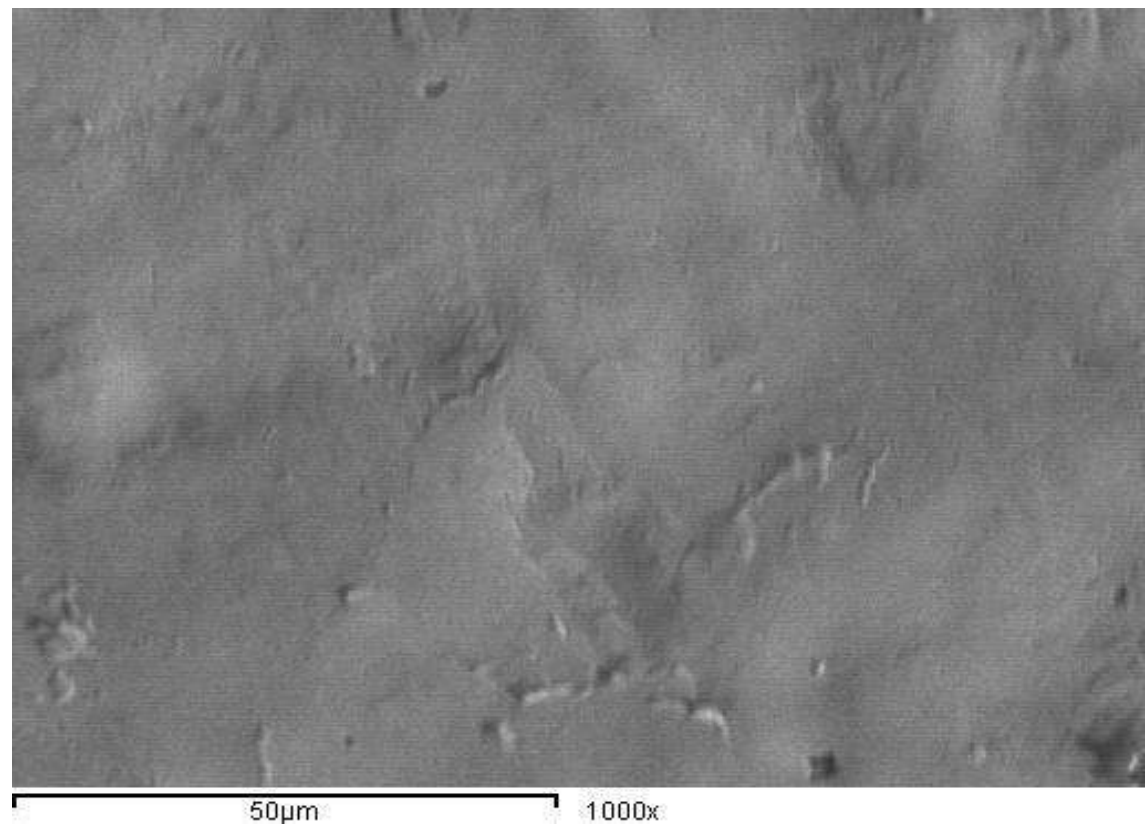

Fig.11. SEM of alginate $+20 \%$ bagasse .

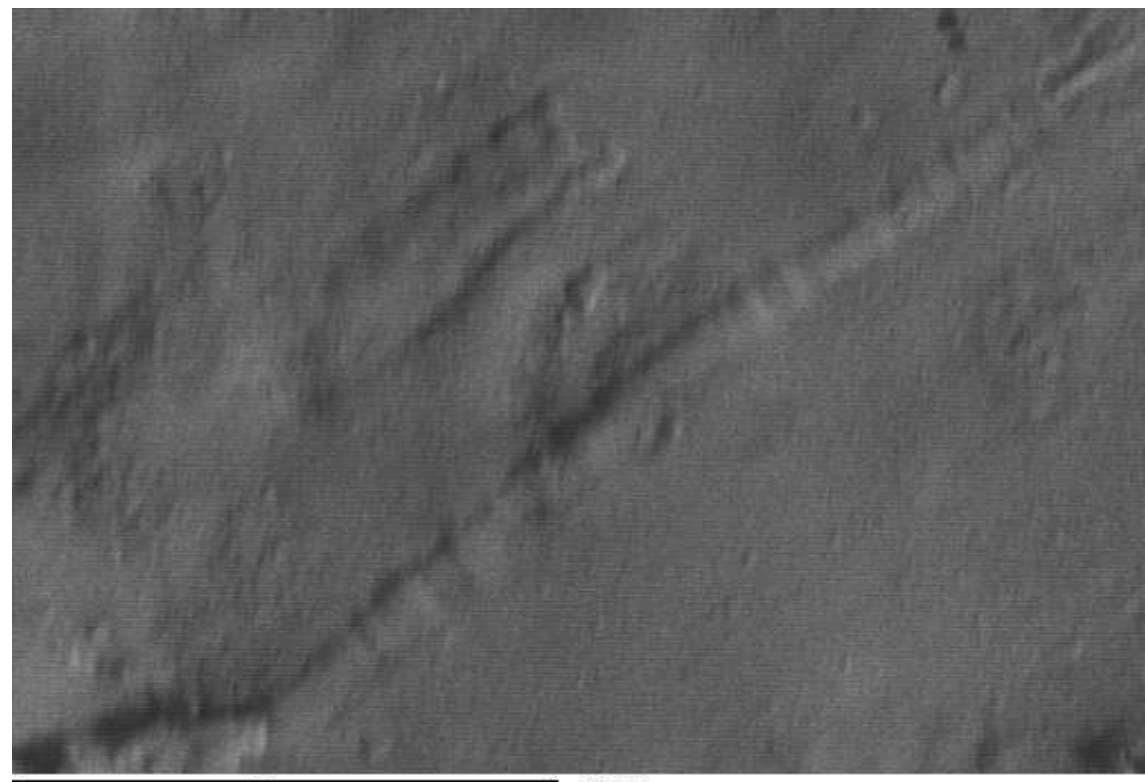

Fig.12. SEM of alginate $+20 \%$ rice straw. 
Water absorption of alginate/CNF nanocomposites

Water sensitivity is one of the major problems of polysaccharide-based films which have limited their application. Water sensitivity of the biobased-films is evaluated by different methods such as monitoring moisture content, water activity and sorption, water solubility, surface hydrophobicity (contact angle) and measuring water vapor permeability ${ }^{(8)}$. Moisture sorption of hydrophilic polymers is an important property since it affects the mechanical and barrier properties.

The transportation of water through polymer composites depends on the chemical nature of the polymer and the filler, the filler dimensions, and polymerfiller interactions, which has been modeled by several researchers using Fick's second law ${ }^{(16)}$.

All of the studied cellulose-containing alginate films had excellent grease barrier properties, i.e. the dyed turpentine did not penetrate films within the $30 \mathrm{~min}$ testing period. Moreover, the good grease barrier properties of alginate explain partly the excellent grease barrier properties of the biocomposite film ${ }^{(17)}$.

The water sorption of the pristine alginate and nanocomposite films was measured and plotted in Fig. $13 \& 14$. The water sorption of pristine alginate film was 135 and $164 \%$ after 1 and 2 weeks, respectively. Due to the high hydrophilicity, alginate has high water sorption properties ${ }^{(18)}$.

The addition of $\mathrm{CNF}$ to the alginate film decreased the water sorption; the water sorption of the $2.5 \% \mathrm{CNF}$ content was about 34 and $42 \%$ lower than that of the pristine alginate film for bagasse and rice straw, respectively. It is known that barrier properties of films are improved when filler has lower permeability and has good dispersion in the matrix as well as a high aspect ratio ${ }^{(8)}$. The incorporation of $\mathrm{CNF}$ significantly reduces the water sorption degree of the alginate matrix because of the relatively low water absorption of CNF. Furthermore, addition of nano-sized cellulose fibers to the alginate matrix prevents the large dimensional change of alginate films and makes it more tortuous, and thus decreases the pathways to water molecules to pass through the film ${ }^{(19)}$. This could explain the improved water sorption properties of alginate films after addition of CNF.

Previous researches also have reported that $\mathrm{CNF}$ improve water resistance of chitosan ${ }^{(20)}$ and gelatin ${ }^{(21)}$ biopolymer matrix in the film form. This reduction in the water sorption of the films is mainly due to the strong hydrogen bond formation between the CNF and the film matrix. The hydroxyl groups of CNF can form strong interactions through hydrogen bonds with the hydroxyl and carboxyl groups on alginate and improve the cohesiveness of biopolymer matrix while decreasing water sensitivity. In other words, water molecules cannot break these strong bonds sufficiently; thus, the water sorption was decreased. The improvement in the hydrophobic character of alginate film with CNF addition can be also attributed to high crystallinity of CNF and the strong hydrogen-

Egypt. J. Chem. 58, No. 3 (2015) 
bonded networks with the polymer matrix were responsible for the water resistance improvement ${ }^{(22)}$.

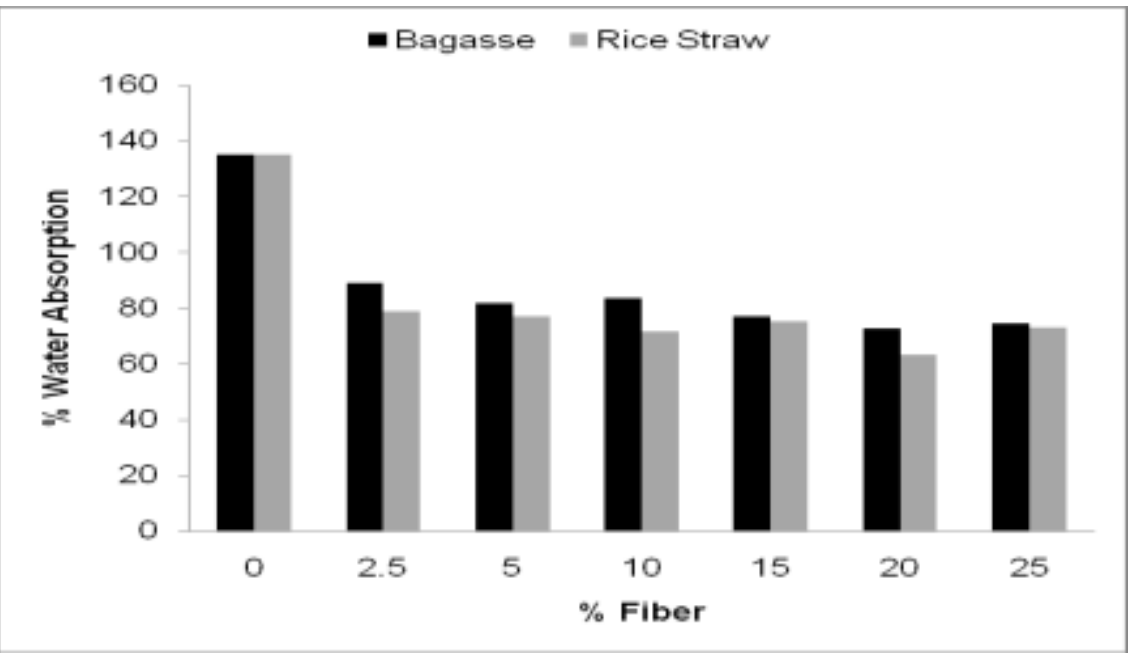

Fig. 13. Water absorption of alginate with $0-25 \%$ bagasse or rice straw CNF after 1 week.

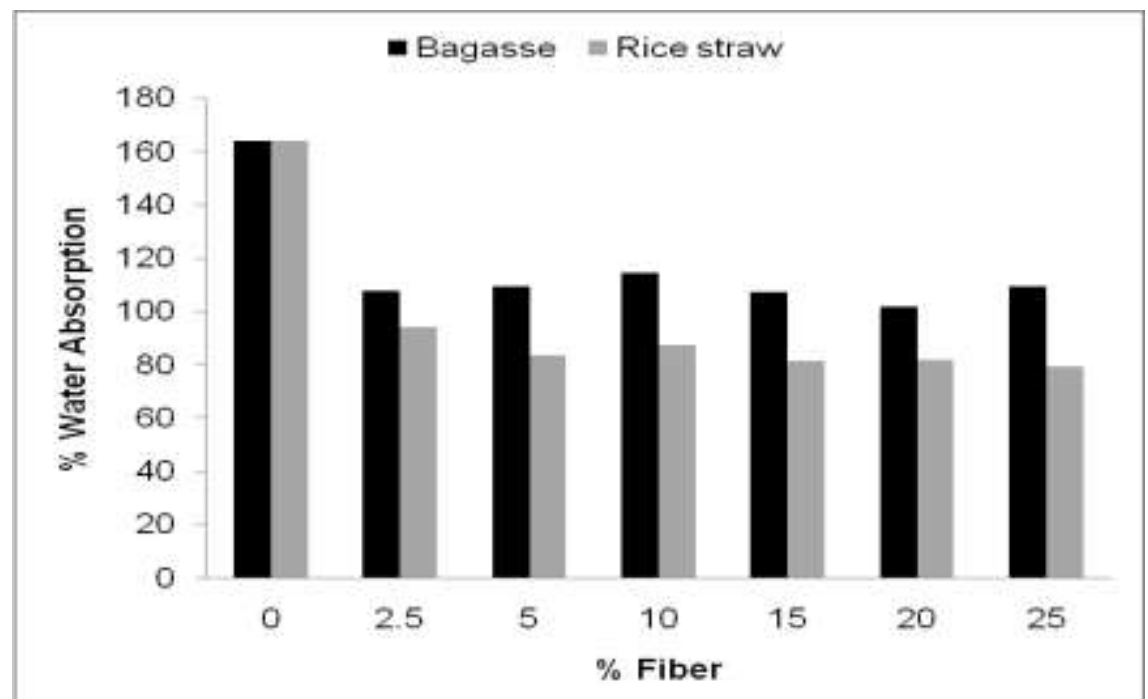

Fig. 14. Water absorption of alginate with $0-25 \%$ bagasse or rice straw CNF after 2 week.

Energy dispersive $X$-ray spectroscopy charaterization

Energy dispersive X-ray spectroscopy (EDX) of films was recorded to identify the expected compositions on a selected rectangle area. EDX

Egypt. J. Chem. 58, No. 3 (2015) 
spectroscopy was used to prove the presence of high concentration of silica in the prepared rice straw nanofiber ${ }^{(23)}$. EDX of $10 \%$ bagasse or $10 \%$ rice straw $\mathrm{CNF}$ are presented in Fig. 15 \& 16 respectively, along with the diffractograms of the alginate CNF films (Fig. 17,18).

All surface sodium ions were changed to calcium ions during the crosslinking. In case of $10 \% \mathrm{CNF}$, a small amount of chlorine is still present in the surface, which indicates that small amount of unreacted $\mathrm{CaCl}_{2}$ remains on the surface of film after washing. Interestingly, all films have similar amounts of calcium ions on their surfaces.

A significant signal at $1.75 \mathrm{keV}$, which is attributed to silicon element, appeared in the EDX spectrum of the rice straw CNF (Fig. 16).

The results of X-ray diffraction could reinforce the existence of good compatibility between the matrix film and the CNF used due to both kinds of strong interactions like hydrogen bonds and ionic interactions.

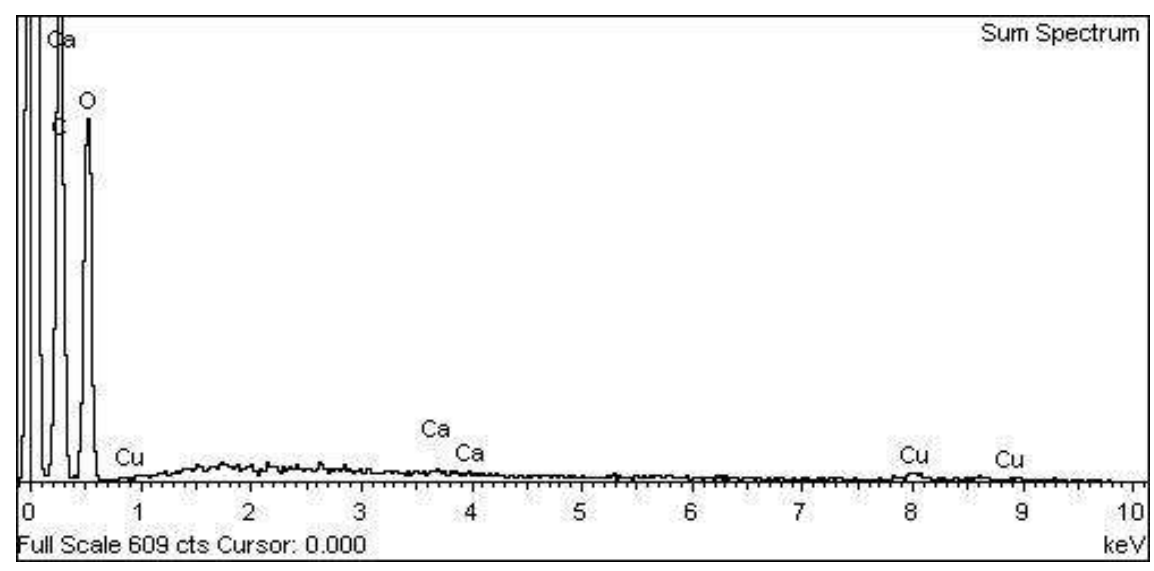

Fig. 15. EDX of bagasse CNF.

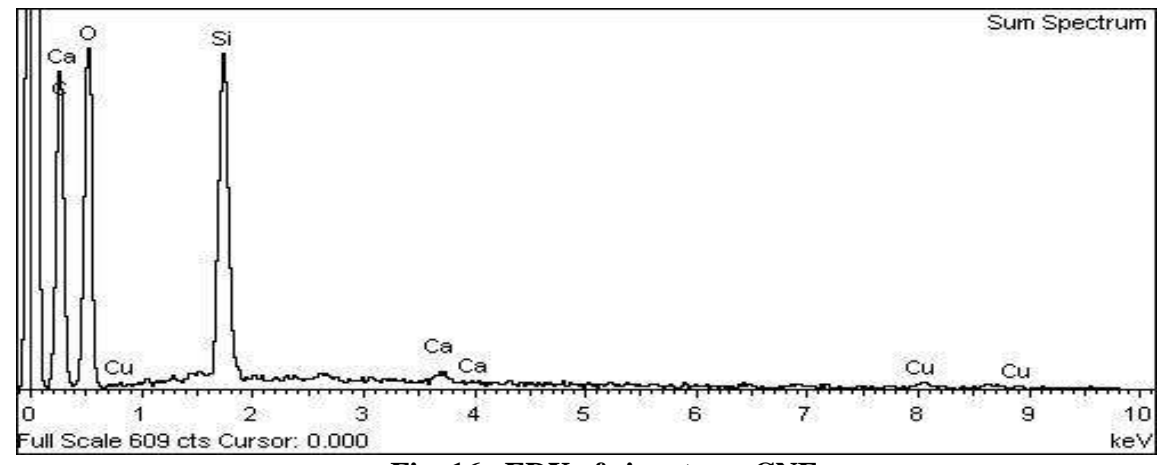

Fig. 16. EDX of rice straw CNF.

Egypt. J. Chem. 58, No. 3 (2015) 


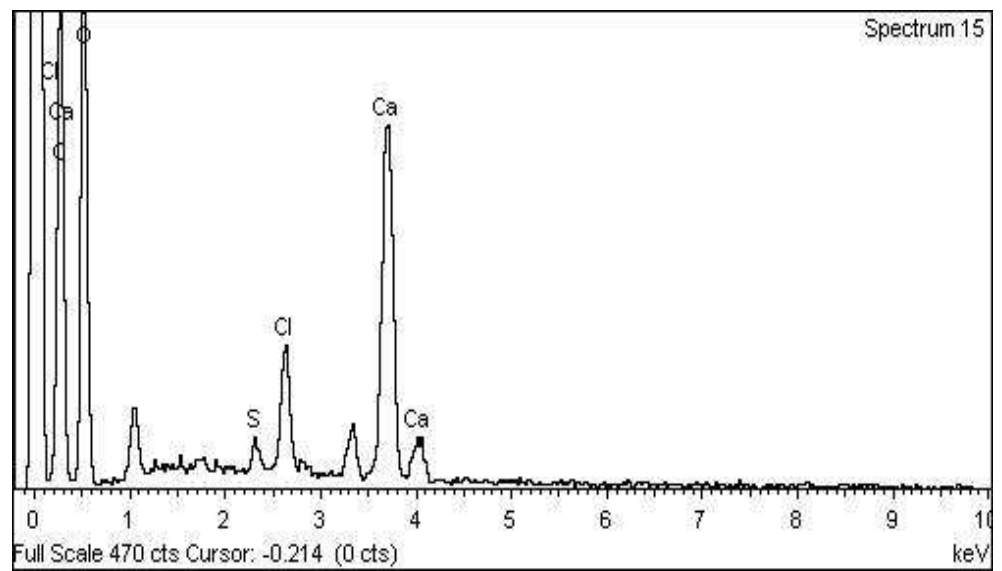

Fig. 17. EDX of alginate with $10 \%$ bagasse CNF.

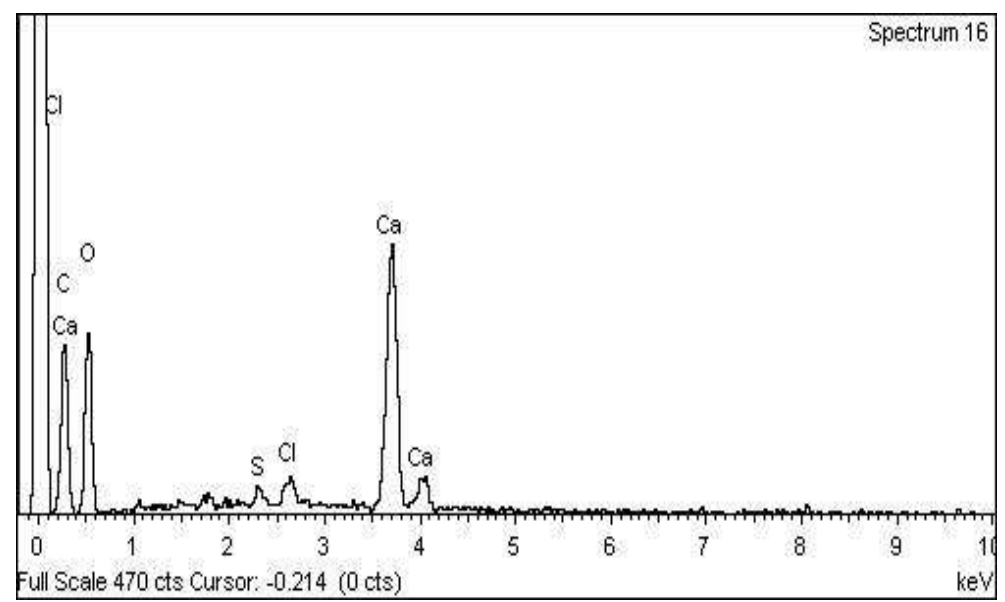

Fig. 18. EDX of alginate with $10 \%$ rice straw CNF.

\section{Conclusions}

Crosslinked alginate/cellulose nanofibers films could be prepared with good homogeneity, especially at nanofibers loadings $<20 \mathrm{wt}$. $\%$.

Bagasse and rice straw nanofibers could be used to improve wet tensile strength and modulus of elasticity of cross-linked alginate polymers. Bagasse nanofibers improved the aforementioned properties more than that occurring on using rice straw nanofibers, probably due to presence of silica nanoparticles in the later. 
Nanocomposites containing rice straw nanofibers had lower water absorption than those containing bagasse nanofibers due to presence of silica nanoparticles within rice straw nanofibers.

Acknowledgement: Financial support for this work was funded by the National Research Center throughout the project number 9140106. The authors express their deep gratitude to the National Research Center for this support.

\section{References}

1. Rubio, M.R. and Ghaly, E.S., In-vitro release of acetaminophen from sodium alginate controlled release pellets. Drug Dev. Ind. Pharm. 20 (6), 1239-1251 (1994).

2. Al-Mussa, S.A., Fara, D.A. and Badwan, A.A., Evaluation of parameters involved in preparation and release of drug loaded in crosslinked matrices of alginate. J. Control. Release, 57 (3), 223-232 (1999).

3. Yotsuyanagi, T., Yoshioka, I., Segi, N. and Ikeda, K., Acid-induced and calciuminduced gelation of alginic acid: Bead formation and $\mathrm{pH}$ dependent swelling. Chem. Pharm. Bull. 39 (4), 1072-1074 (1991).

4. Kalia, S., Kaith, B.S. and Kaur, I., Pretreatments of natural fibers and their application as reinforcing material in polymer composites- A review. Polym. Eng. Sci. 49 (7), 1253-1272 (2009).

5. Siro, I. and Plackett, D., Microfibrillated cellulose and new nanocomposite materials: A review. Cellulose, 17 (3), 459-494 (2010).

6. Hassan, M.L. Bagasse and Rice straw Nanocellulosic Materials and Their Applications. In: Handbook of Polymer Nanocomposites. Processing, Performance and Application, Volume C, Polymer Nanocomposites of Cellulose Nanoparticles, Pandey, J.K., Takagi, H., Nakagaito, A.N., Kim, H.-J. (Ed.), Springer, 2015, 200 p. (2015).

7. Hassan , M.L., Hassan, E.A. and Oksman, K.N., Effect of pretreatment of bagasse fibers on the properties of chitosan/microfibrillated cellulose nanocomposites. $J$. Mater. Sci. 46 (6), 1732-1740 (2011).

8. Abdollahi, M., Alboofetileh, M., Behrooz, R., Rezaei, M. and Miraki, R., Reducing water sensitivity of alginate bio-nanocomposite film using cellulose nanoparticles. Int. J. Biol. Macromol. 54, 166- 173 (2013).

9. Cao, X., Chen, Y., Chang, P.R., Stumborg, M. and Huneault, M.A., Green composites reinforced with hemp nanocrystals in plasticized starch. J. Appl. Polym. Sci. 109, 3804-3810 (2008).

10. Favier, V., Dendievel, R., Canova, G., Cavaillé, J.-Y. and Gilormini, P., Simulation and modeling of 3D percolating structures: case of latex matrix reinforced by a network of cellulose fibers. Acta Mater. 45 (4), 1557-1565 (1997).

11. Hassan, M.L., Oksman, K., El-Wakil, N.A., Hassan, E.A. and Fadel, S.M., Preparation and characterization of cellulose whiskers from bagasse, rice straw, and sugar beet

Egypt. J. Chem. 58, No. 3 (2015) 
pulps and their use in alginate nanocomposites. $10^{\text {th }}$ International Conference on Wood \& Biofiber Plastic Composites , 361-371 (2009).

12. Fernandes, S.C.M., Freire, C.S.R., Silvestre, A.J.D., Neto, C.P., Gandini, A., Berglund, L.A. and Salme'n, L., Transparent chitosan films reinforced with a high content of nanofibrillated cellulose. Carbohyd. Polym. 81, 394-401 (2010).

13. Pereda, M., Amica, G., Rácz, I. and Marcovich, N.E., Structure and properties of nanocomposite films based on sodium caseinate and nanocellulose fibers. J. Food Eng. 103, 76-83 (2011).

14. Azizi Samir, A.S., Alloin, F. and Dufresne, A., Review of recent research into cellulosic whiskers, their properties and their application in nanocomposite field. Biomacromol. 6 (2), 612-626 (2011).

15. Wu, T., Farnood, R., O'Kelly, K. and Chen, B., Mechanical behavior of transparent nanofibrillar cellulose-chitosan nanocomposite films in dry and wet conditions. $J$. Mechanical Behavior of Biomedical Materials, 32, 279 - 286 (2014).

16. Asaoka, K. and Hirano, S., Diffusion coefficient of water through dental composite resin. Biomat. 24, 975-979 (2003).

17. SirviÖ, J.A., Kolehmainen, A., Liimatainen, H., Niinimäki, J. and Hormi, E.O., Biocomposite cellulose-alginatefilms: Promising packaging materials. Food Chemistry, 151, 343-351 (2014).

18. Olivas, G.L. and Barbosa-Cánovas, G.V., Alginate-calcium films: Water vapor permeability and mechanical properties as affected by plasticizer and relative humidity. LWT- Food Sci. Technol. 41, 359-366 (2008).

19. Huq, T., Salmieri, S., Khan, A., Khan, R.A., Le Tien, C., Riedl, B., Fraschini, C. and Bouchard, J., Uribe-Calderon, J.; Kamal M.R. and Lacroix, M., Nanocrystalline cellulose (NCC) reinforced alginate based biodegradable nanocomposite film. Carbohyd. Polym. 90, 1757- 1763 (2012).

20. Li, Q., Zhou, J. and Zhang, L., Structure and properties of the nanocomposite films of chitosan reinforced with cellulose whiskers. J. Polym. Sci. 47 (11), 1069-1077 (2009).

21. Hassan, M.L., Fadel, S.M., El-Wakil, N.A. and Oksman, K., Chitosan/rice straw nanofibers nanocomposites: preparation, mechanical, and dynamic thermomechanical properties. J. Appl. Polym. Sci. 125, E216-E222 (2012).

22. de Paula, E.L., Mano, V. and Pereira, F.V., Influence of cellulose nanowhiskers on the hydrolytic degradation behavior of poly(D,L-lactide). Polym. Degrad. Stab. 96 (9), 1631-1638 (2011).

23. Hassan, M.L., Mathew, A.P., Hassan, E.A., El-Wakil, N.A. and Oksman, K., Nanofibers from bagasse and rice straw: Process optimization and properties. Wood Sci. Technol. 46, 193-205 (2012). 


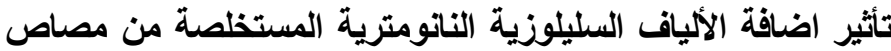

$$
\begin{aligned}
& \text { القصب و قش الأرز على الخواص الفيزيقية و الميكاتيكية لأفلام } \\
& \text { الألجينات النانومترية }
\end{aligned}
$$

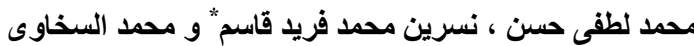

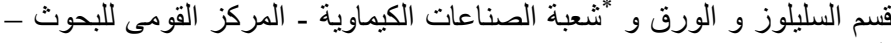

$$
\begin{aligned}
& \text { الجيزة - مصر . السلوز و الور }
\end{aligned}
$$

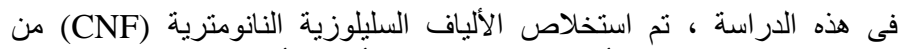

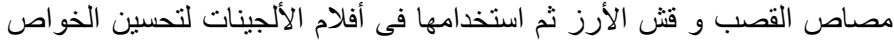

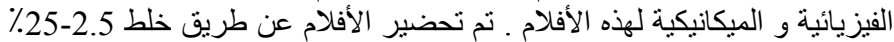

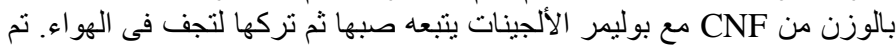

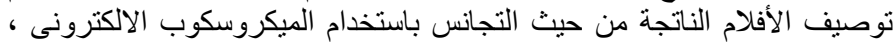
قوة الثد و معامل المرونة فى الحالتين الجافة و الرطبة، ثم قدرة الأفلام على الثى

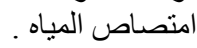

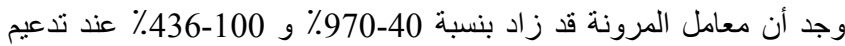

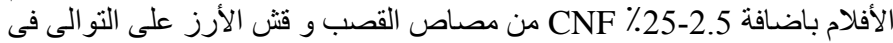

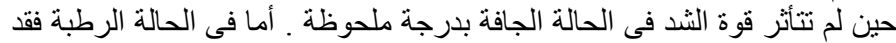

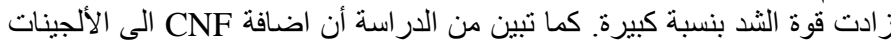
أدت الى تقليل امتصاص المياه في الأفلام الناتجة. 